\title{
Mostra Sem Censura
}

Por: Ana Karoline de Moraes Silva ${ }^{1}$ 
A Mostra sem Censura foi um movimento que reuniu, durante o mês de outubro de 2017, alguns dos espaços de arte independentes de Florianópolis para articular ações artísticas e diversificadas em resposta às censuras, cancelamento e fechamento de diversas exposições que aconteceram no país. Em princípio, a ideia foi elaborar uma agenda nestes espaços de arte de Florianópolis com ações que dialogassem com a exposição Queermuseu que havia sido fechada em Porto Alegre. A equipe foi constituída de Juliana Crispe, Francine Goudel, Isadora Stahelin, Anna Moras, Chay Luge, João Aires e Monique Cavalcanti, representando os espaços Armazém/Coletivo Elza, Nacasa Coletivo Artístico, Embarcação, O Sítio, Agenda.

A mobilização destes gestores artísticos incluiu a criação o CEAl - Circuito de Espaços Independentes de Florianópolis -, que abrange não apenas as artes visuais mas, também, música, teatro, dança, arte urbana, entre outros.

Cada um dos espaços promoveu durante esse mês um evento: abertura e ações semanais no Bar Feminista La Kahlo, exibição de filmes n'O Sítio, Feira Degenerada no Espaço Armazém, ocupação na Rua Hercílio Luz com ações performáticas organizados pelo espaço Embarcação e a Exposição Mostra sem Censura no Nacasa.

ISSN: 2175-2346

1 annamoraess@gmail.com 


\section{Exposição Mostra sem Censura}

Com a experiência anterior na produção do XI Salão Nacional Victor Meirelles* ao lançar um edital sem seleção ou curadoria onde todos os trabalhos fossem aceitos, a Exposição Mostra sem Censura no Nacasa seguiu o mesmo modelo de convocatória de trabalhos do salão: sem seleção, sem curadoria e desta vez enfatizando "sem censura", como forma de posicionamento contra às censuras acontecendo às artes e artistas no país. A convocatória, com o tema "sem censura", foi aberta entre os dias 04 a 18 de outubro de 2017 e obteve inscrição de 210 artistas e um montante de cerca de 580 trabalhos entre desenho, gravura, fotografia, colagem, vídeo, instalação, escultura, performance e publicação. Participaram artistas de diferentes estados do Brasil como Piauí, Bahia, Minas Gerais, São Paulo, Rio Grande do Sul, Paraná, Santa Catarina, Pernambuco, além de outros países como México, Argentina, Uruguai, Costa Rica, Colômbia, Peru, Espanha e Portugal. Houve a tradução da convocatória para o idioma espanhol o que pode justificar a variedade de artistas internacionais que participaram. Para participar bastava enviar a imagem dos trabalhos via arquivo digital, pois a exposição foi produzida com as impressões dos trabalhos, além da elaboração de um catálogo virtual. Cada artista teve seu trabalho impresso em uma página, de mesmo modo que foi diagramado o catálogo. Os vídeos foram exibidos em duas TVs planas e todos os trabalhos foram projetados em uma parede da galeria. A abertura da Mostra Sem Censura aconteceu no dia 25 de outubro às 19:00hs, na nossa sede.

\section{CensuradXs}

Nosso evento, poucos dias antes da abertura da mostra, foi bloqueado no Facebook por denúncia de duas imagens e Anna Moraes teve seu perfil bloqueado por $24 \mathrm{~h}$ por estar postando pela página do Nacasa. De mesmo modo, não obtivemos apoio nem divulgação desse movimento artístico e coletivo em nenhuma mídia local.

\section{(re)Ações}

Como gestores de espaços artísticos independentes, atuantes na cidade e no Estado, promover a MOSTRA SEM CENSURA funcionou como um manifesto da autonomia da arte, tanto contra às censuras que estão acontecendo no país, como na organização de uma mostra sem interferência de espaços institucionalizados de arte ou do governo. A importância da união dos espaços artísticos para trabalhar em prol da arte e da cultura com maior aproximação dos artistas é uma ação relevante e de extrema importância no contexto atual.

Para a mostra a ideia foi reunir imagens de obras e ações que desestabilizem as noções estéticas pregadas pelas organizações conservadoras do país e que destacassem, dialogassem e promovessem reflexões relacionados ao universo LGBTQI+, à sexualidade, à legalização do aborto entre outros temas emergentes. 


\section{O coletivo}

O Nacasa é um coletivo de artistas situado no bairro da Trindade em Florianópolis onde sete artistas dividem a sede que é uma casa alugada. Cada artista utiliza uma sala como ateliê e/ou sala de aula e ainda contamos com uma galeria, na sala principal, que promove exposições mensais. Todos os custos do espaço são divididos entre os artistas, sem qualquer patrocínio ou incentivo de fora. O coletivo iniciou em 2010 com alguns professores de desenho, pintura, ilustração, gravura, que lecionavam no Centro Integrado de Cultura (CIC) e que buscaram um lugar para continuar suas atividades enquanto o $\mathrm{CIC}$ ficou fechado para reformas. Dos integrantes que ainda atuam desde essa época estão Diego de los Campos, Leandro Lopes de Sousa e Meg Tomio Roussenq. O grupo, ao longo destes anos, recebeu vários artistas para compartilhar o espaço.

- Integrantes do coletivo NaCasa: Anna Moraes, Diego de los Campos, Gabi Orofino, Leandro Lopes de Sousa, Meg Tomio Roussenq, Radji e Talita Esquivel.

- Convocatória: Anna Moraes e Isadora Stahelin

- Responsáveis pela galeria: Anna Moraes e Diego de los Campos

- Tradução da convocatória para o espanhol: Isadora Stahelin

- Produção (emails e redes sociais): Anna Moraes e Isadora Stahelin.

- Produção do catálogo virtual: Anna Moraes, Radji Shucman e Juliana Crispe

- Montagem da exposição: Anna Moraes, Francine Goudel, Radji Shucman, Diego de los Campos e Juliana Crispe.

\section{Seleção de trabalhos da Mostra Sem Censura (para a Revista Palíndromo)}

Dentre mais de 580 trabalhos de 210 artistas que participaram da convocatória da Mostra Sem Censura, buscou-se contemplar variadas linguagens artísticas com trabalhos de autoras/autores que propusessem um diálogo entre temas contemporâneos emergentes com imagens significativas que atualizassem discursos e posicionamentos de outrora, em um embate potente e poético que perscruta o ser/ fazer arte em tempos atuais sem perder a referência do passado, em um movimento histórico, cultural e social que possibilita a consciência da construção do porvir, do devir e dos múltiplos modos do vir a ser. 

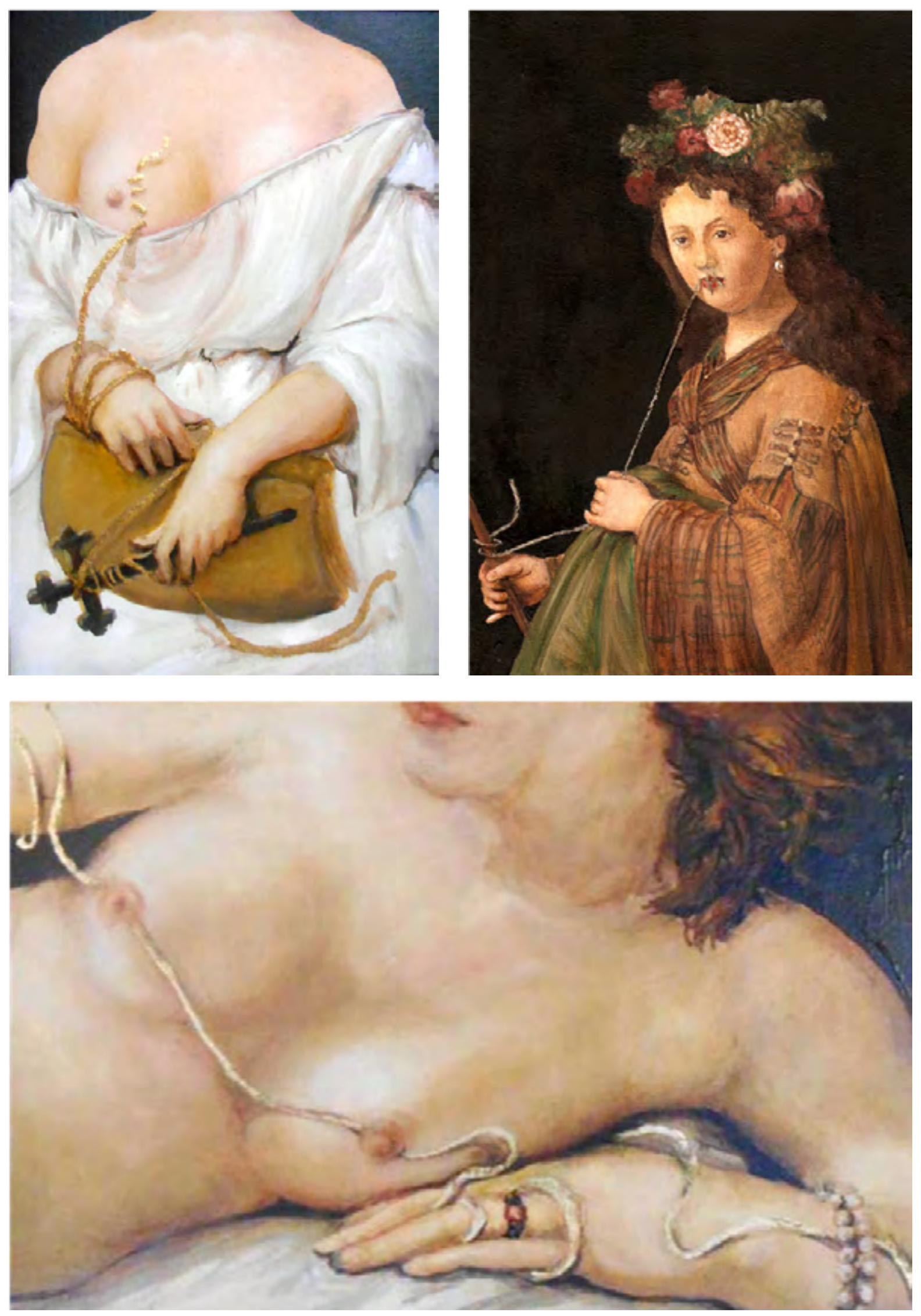

ANASOR ED SEAROM (São Paulo | SP) anasoredsearomagmail.com

Hayez Series - Assédio, 2016 óleo e ouro sobre tela 30 × $20 \mathrm{~cm}$ Enlaces, 2017 óleo e ouro sobre tela $20 \times 30 \mathrm{~cm}$ Rembrandt Series, 2009 óleo e ouro sobre tela $30 \times 20 \mathrm{~cm}$ 


\section{Mostra Sem Censura}
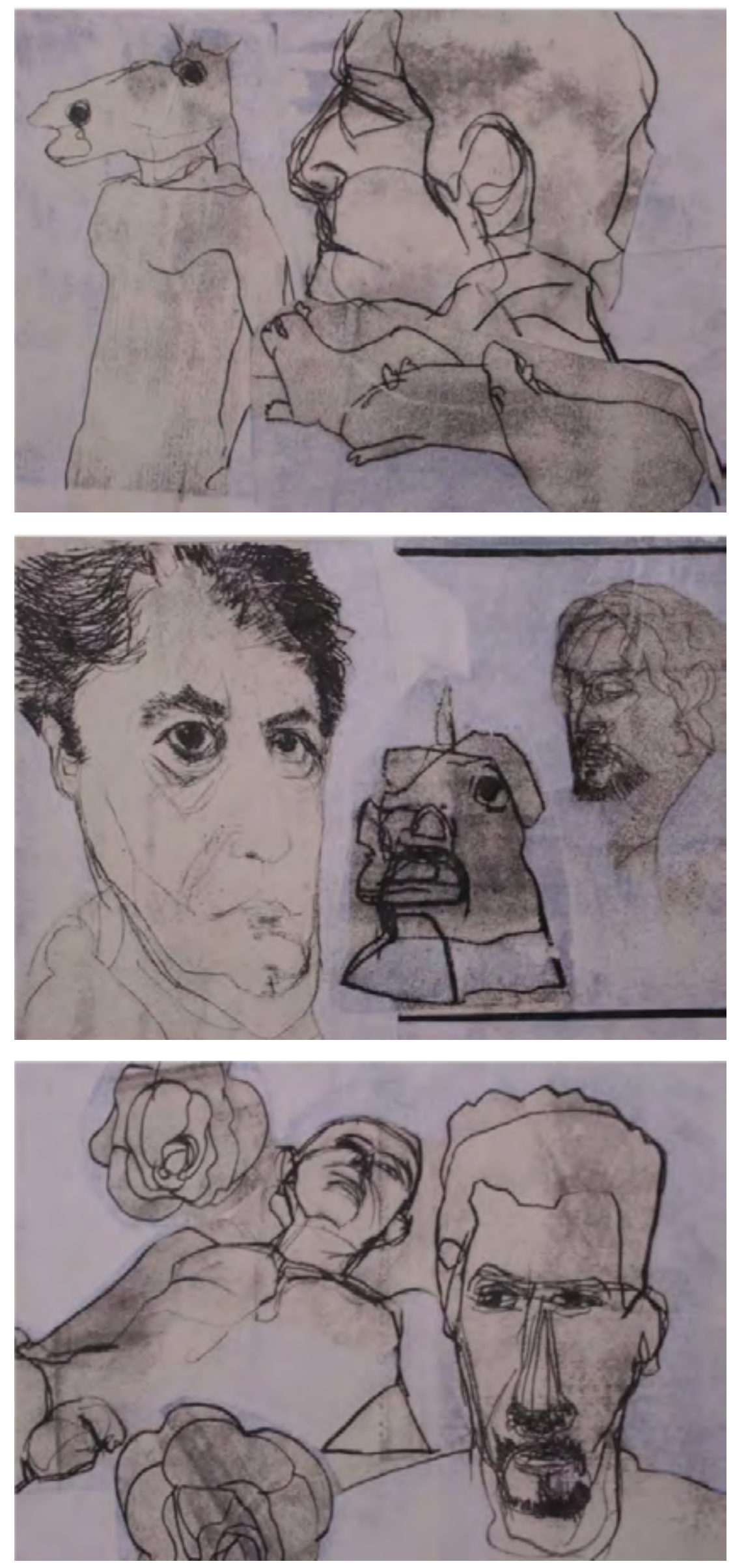

ANTONIO GOPER

(São Paulo | SP)

antoniogoper@gmail.com

O Minotauro - Sonho 1 ,

Sonho 2, Sonho 3, 2015

Técnica Mista

$29,5 \times 42 \mathrm{~cm}$ (cada) 

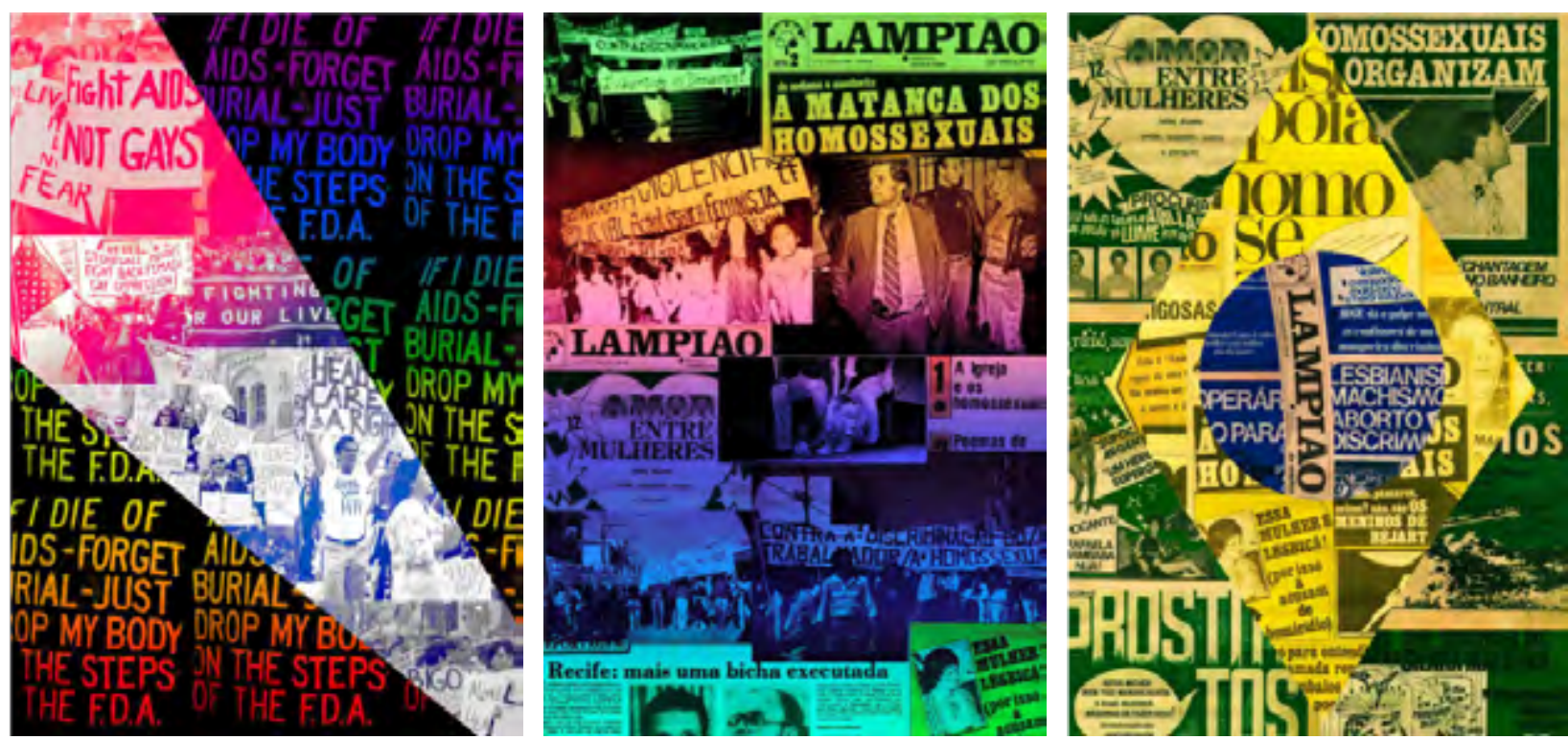

CAMILA TURI (Sorocaba | SP) camila_turiahotmail.com

If $\mathrm{i}$ die of aids, 2017 colagem digital, $41 \times 30 \mathrm{~cm}$

Colagem baseada em protestos ocorridos no Estados Unidos durante a crise de AIDS nos anos 80. A doença se espalhou entre homens gays com maior força e o governo de Ronald Reagan se recusava a prestar socorro devido à sexualidade das vitimas.

$\bigcirc$ título e a frase no fundo preto foram retirados de uma foto retratando o pintor e fotógrafo David Wojnarowicz, falecido em 1992 por ter contraído a doença.

Sem título, 2017 colagem digital, $30 \times 21 \mathrm{~cm}$

Experimentação e estudo feito com manchetes do jornal Lampião da Esquina e imagens representando a repressão sentida pela comunidade LGBT brasileira nos anos da ditadura junto com outros grupos considerados "sexualmente subversivos". Sinto que essa violência em especifíco é muitas vezes ignorada ao discutirmos a história do país.

Aquarela do Brasil, 2017 colagem digital, $42 \times 30 \mathrm{~cm}$

Sobreposições das páginas iniciais do jornal Lampião da Esquina recortadas para constituir a bandeira do Brasil.

A intenção foi representar o país através das publicações hora críticas e satíricas, hora biográficas feitas por, e para, a comunidade LGBT. 

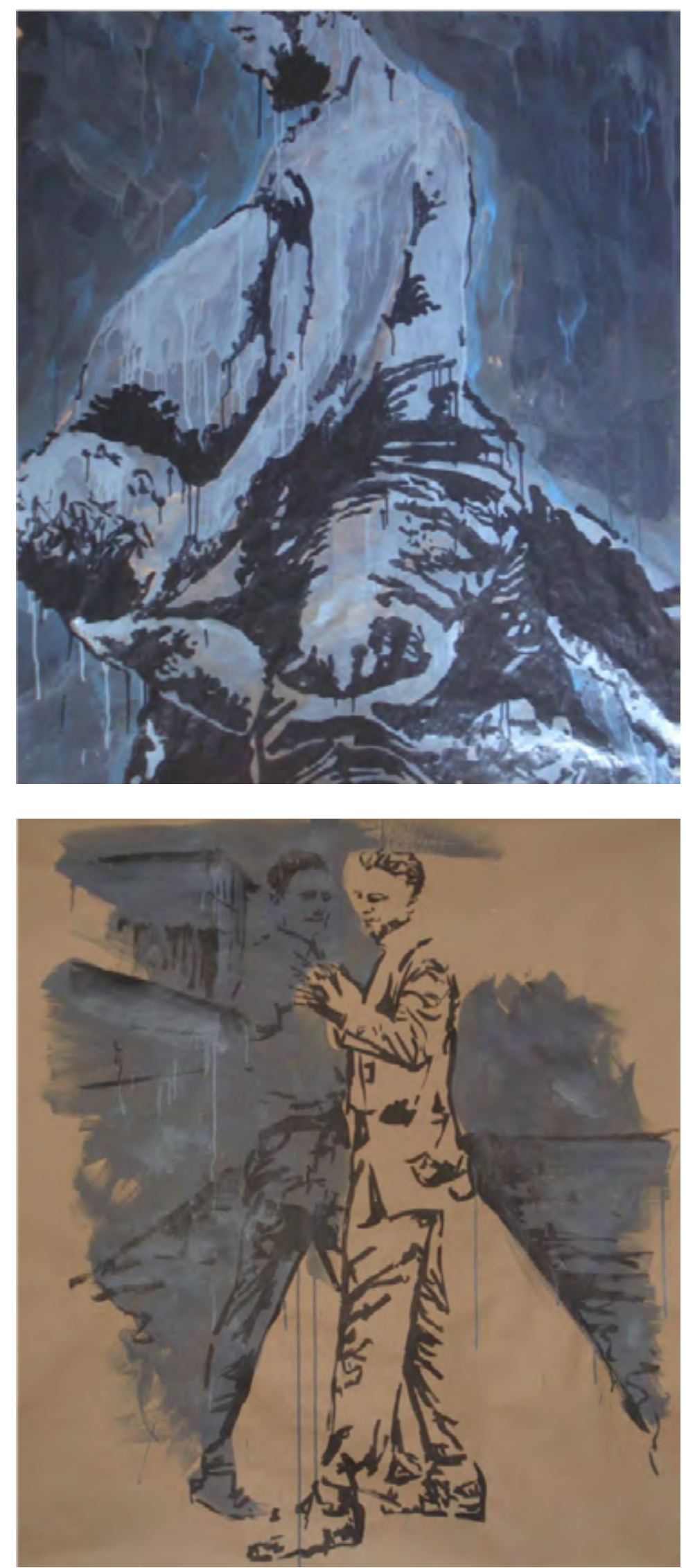

FABIANO DEVIDE (Rio de Janeiro | RJ) fabianodevide@uol.com.br www.fabianodevide.blogspot.com

\section{ME FAÇA VER DE OLHOS FECHADOS} (Série Lutadores), 2011 Acrílica sobre papel craft $135 \times 110 \mathrm{~cm}$

SEM TÍTULO (Séries dançarinos), 2011 Acrílica sobre papel craft, $120 \times 110 \mathrm{~cm}$

As obras foram produzidas no contexto da Escola de Artes Visuais do Parque Lage/RJ (EAV-Pq Lage), a partir de investigação acerca das masculinidades presentes nas práticas corporais, com foco nas lutas e danças, por considerar essas modalidades, respectivamente, áreas de reserva masculina e feminina na cultura corporal brasileira. Nesse sentido, a partir de uma perspectiva Queer, ambas as obras buscam apresentar as possibilidades de múltiplas masculinidades presentes neste cenário, fluídas, e transitórias, que escapam dos estereótipos de uma masculinidade hegemônica e de uma heterossexualidade compulsória. 


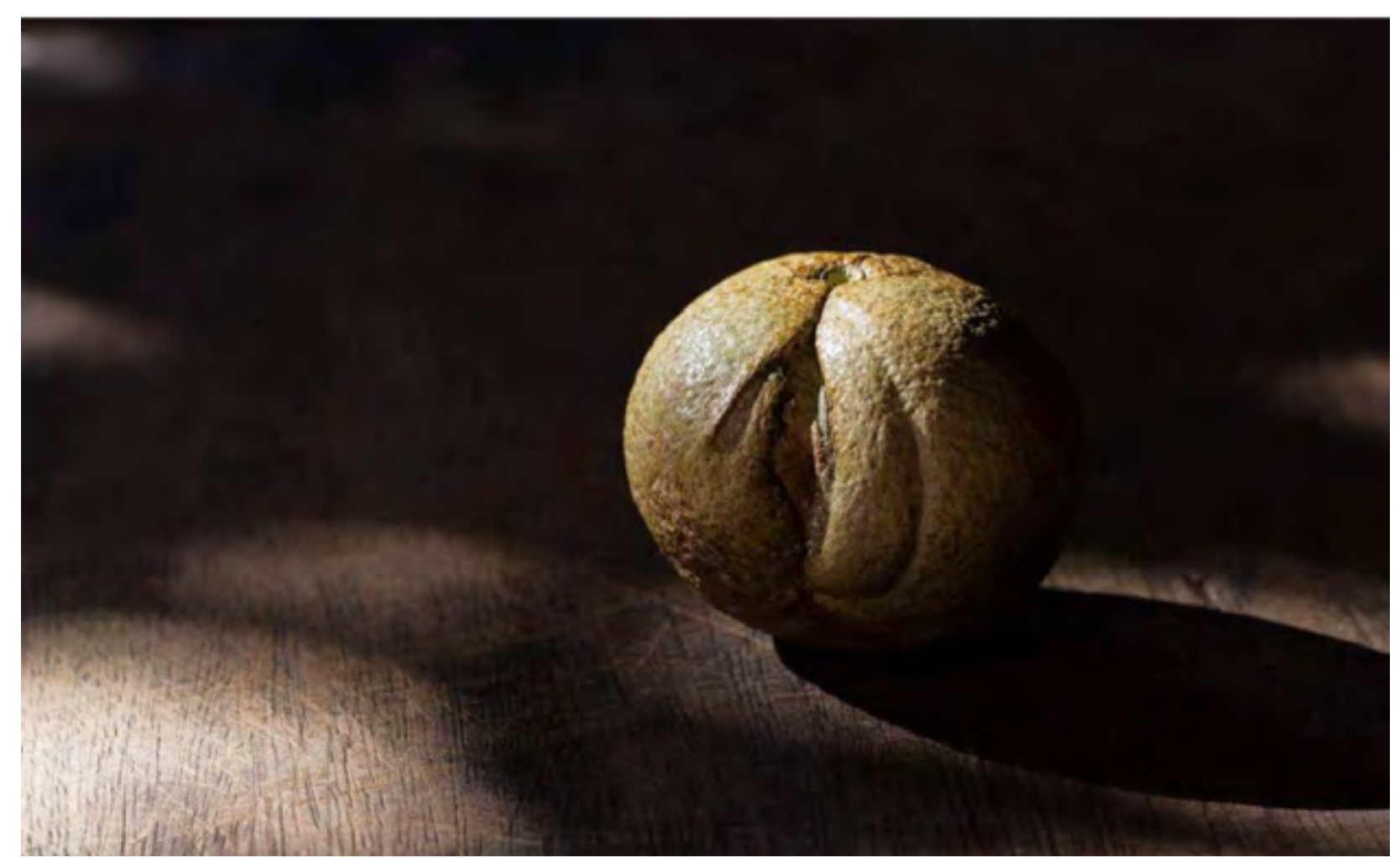

FÁBIO FLORENTINO (Iperó | SP) fabioflorentino@hotmail.com A Limão Fotografia 


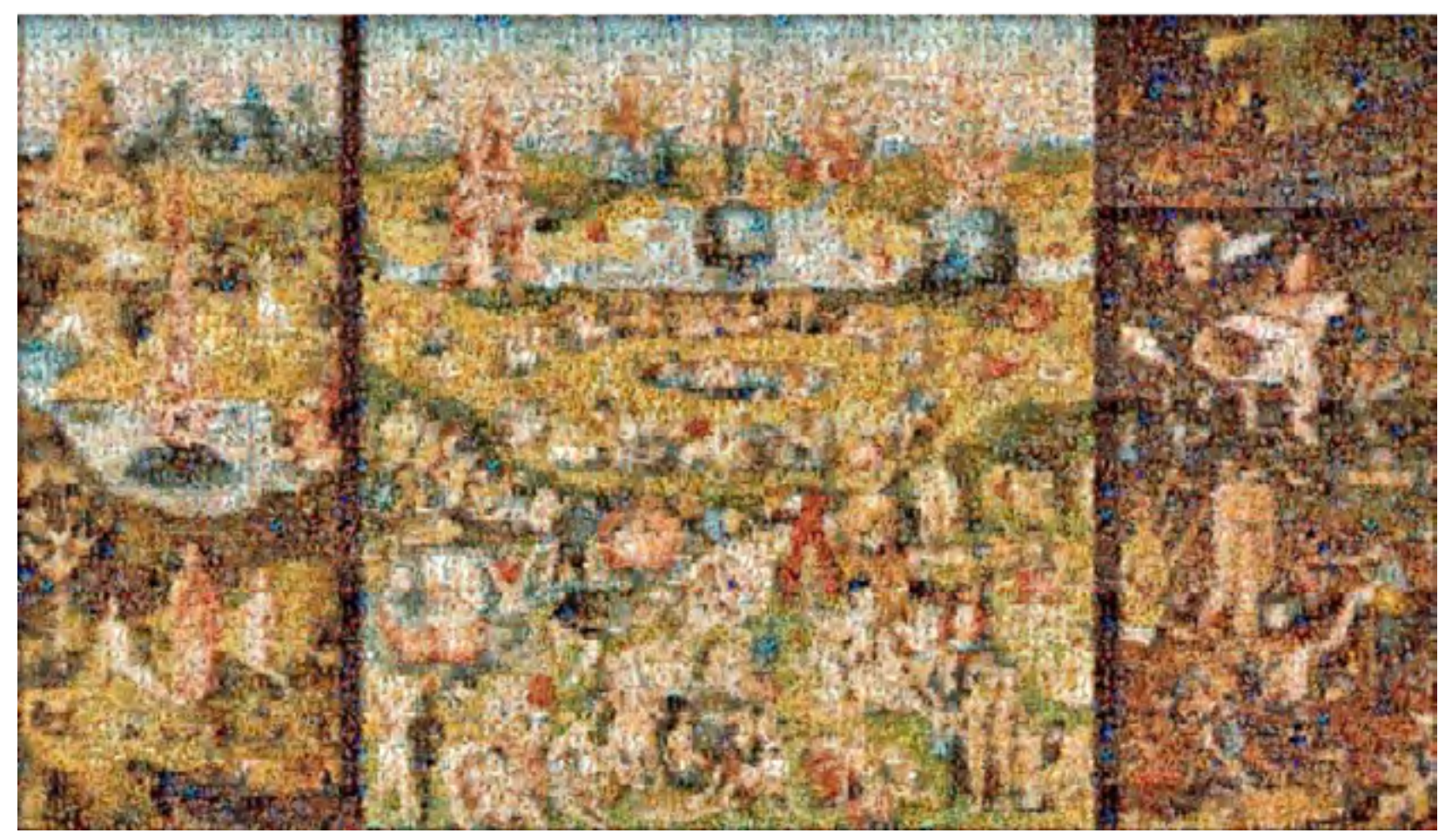

HD (Hernani Dimantas) (São Paulo | SP)

hdimantas@gmail.com

https://hdimantas.wordpress.com/

http://hdimantas.wix.com/hdimantas

http://hd.store.art.br/

Jardim das delícias cibernéticas, 2017

Remix do "Jardim das Delícias Terrenas" de Hieronymus Bosch, metapixelado

(fotomosaico) com base de imagens de pornografia e impressão em tela

$120 \times 70 \mathrm{~cm}$ 


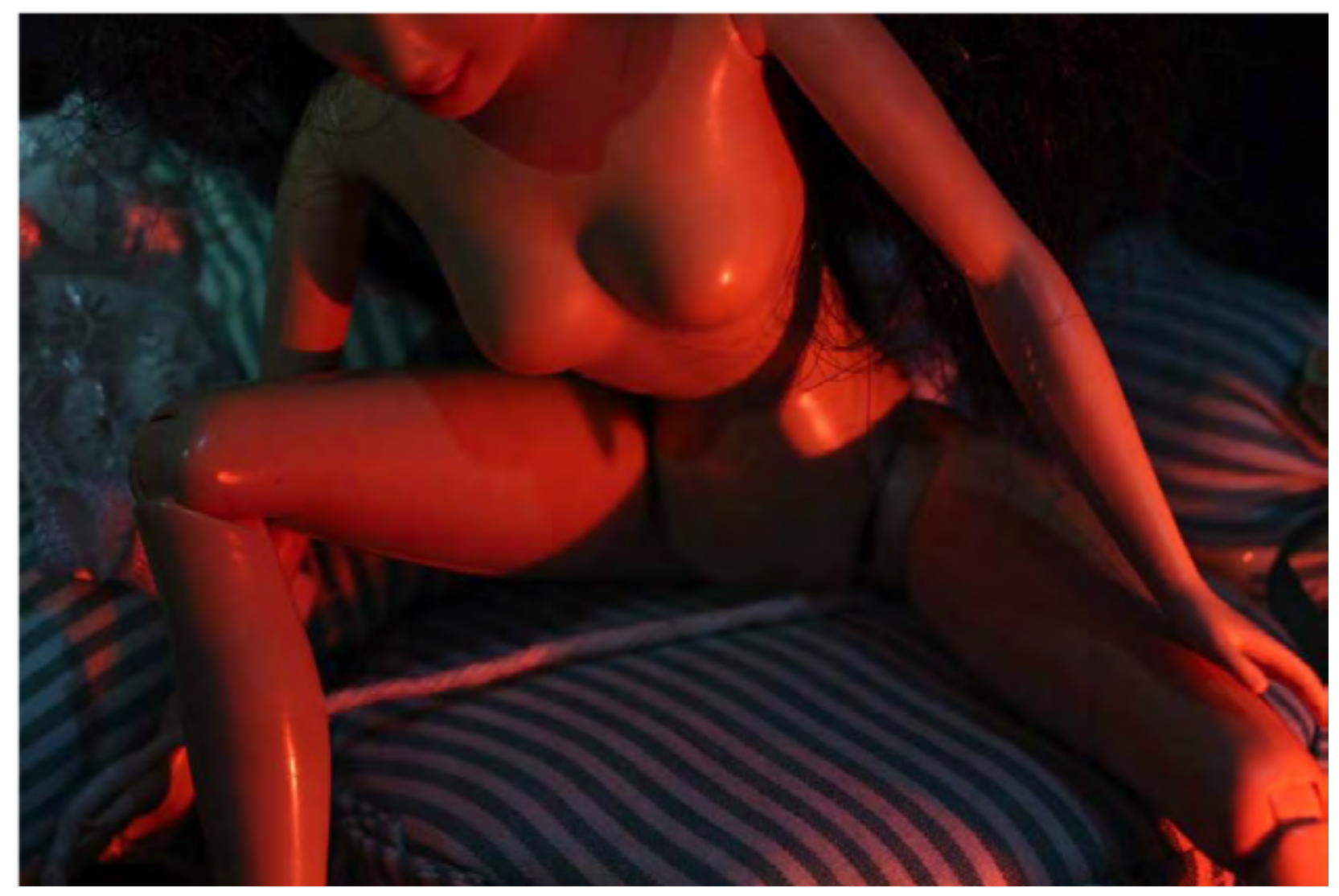

HINGRID CLASEN (São José | SC) hingrid.clasen@gmail.com

Teste do sofá \#2, s/d Fotografia $20 \times 30 \mathrm{~cm}$ 

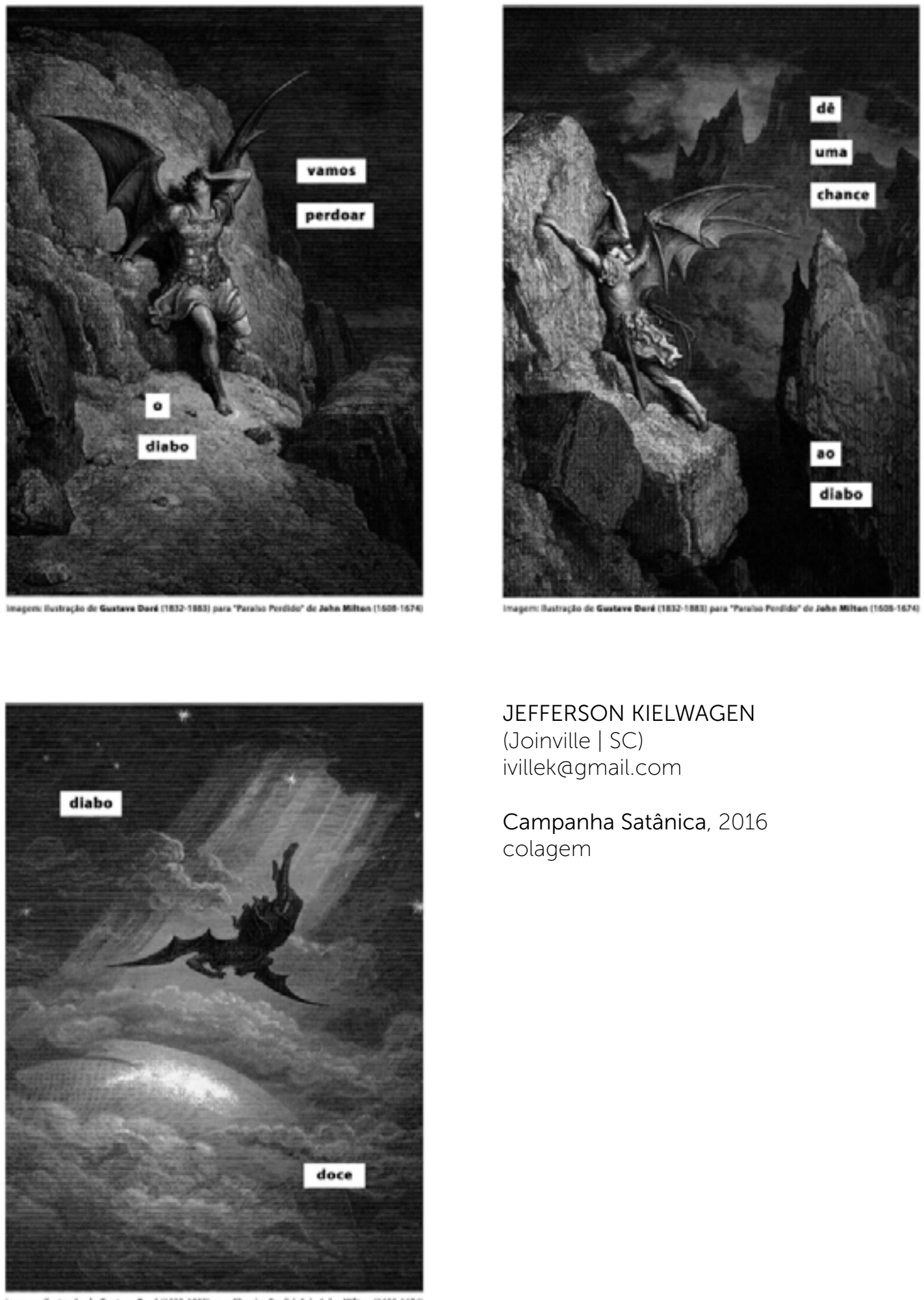

JEFFERSON KIELWAGEN

(Joinville | SC)

ivillek@gmail.com

Campanha Satânica, 2016

colagem 

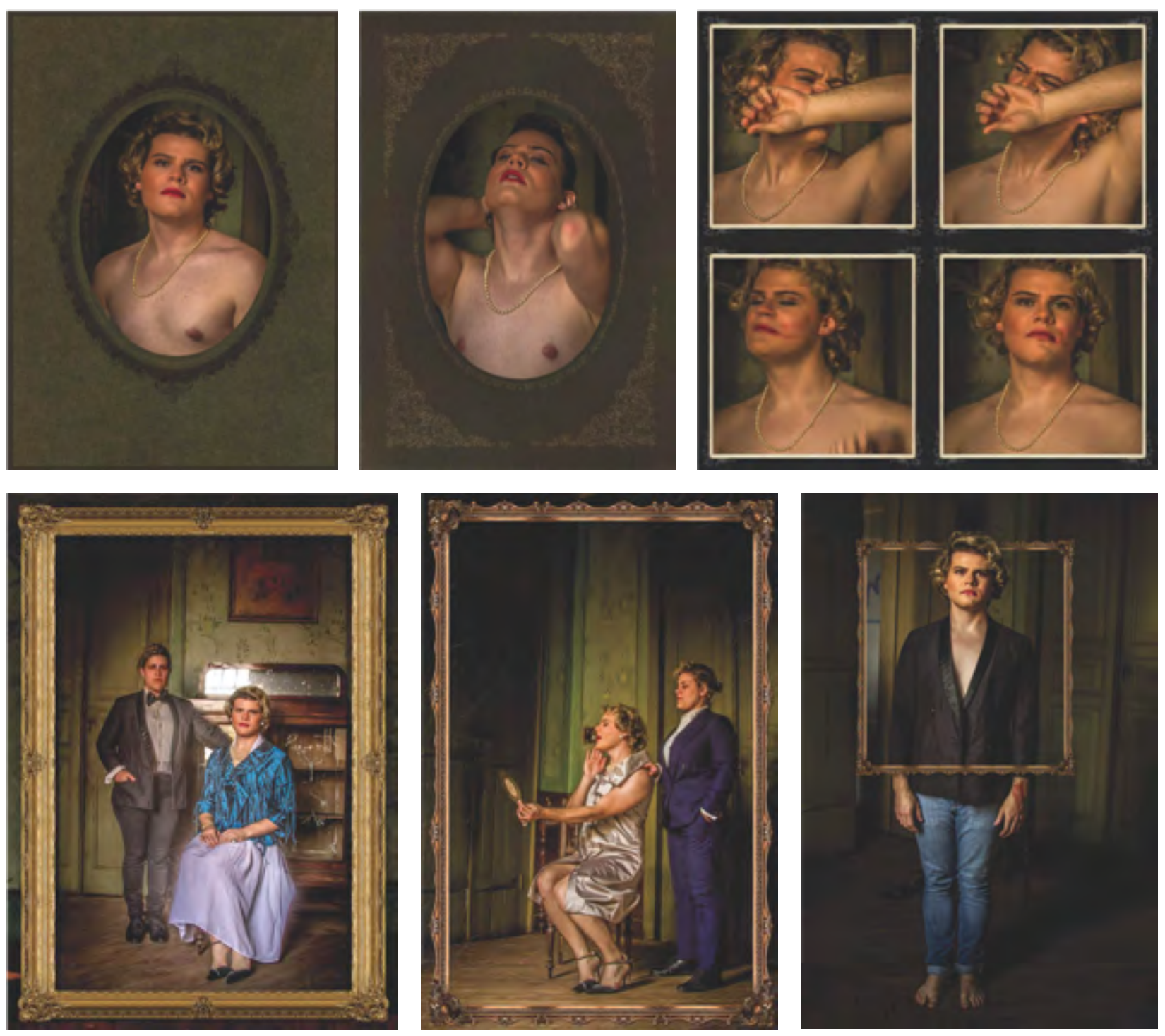

JOÃO BARIM

(Espírito Santo do Pinhal | SP) joao.barim@gmail.com

(re)flexões do gênero (série), 2016

Fotografia digital

$80 \times 110 \mathrm{~cm} ; 30 \times 40 \mathrm{~cm} ; 30 \times 40 \mathrm{~cm}$; $50 \times 75 \mathrm{~cm} ; 50 \times 75 \mathrm{~cm} ; 60 \times 60 \mathrm{~cm}$.

(re)flexões do gênero é um trabalho que propõe uma reflexão sobre sexualidade e gênero adotando uma estética que remete aos tempos em que a fotografia e a pintura não ofereciam espaço para retratar essas questões. É um trabalho que encara o público,

num momento em que os direitos conquistados pela mulher

e pela comunidade LGBTQ estão cada vez mais ameaçados e incertos. (re)flexões fala sobre a coragem da certeza. 


\section{Mostra Sem Censura}

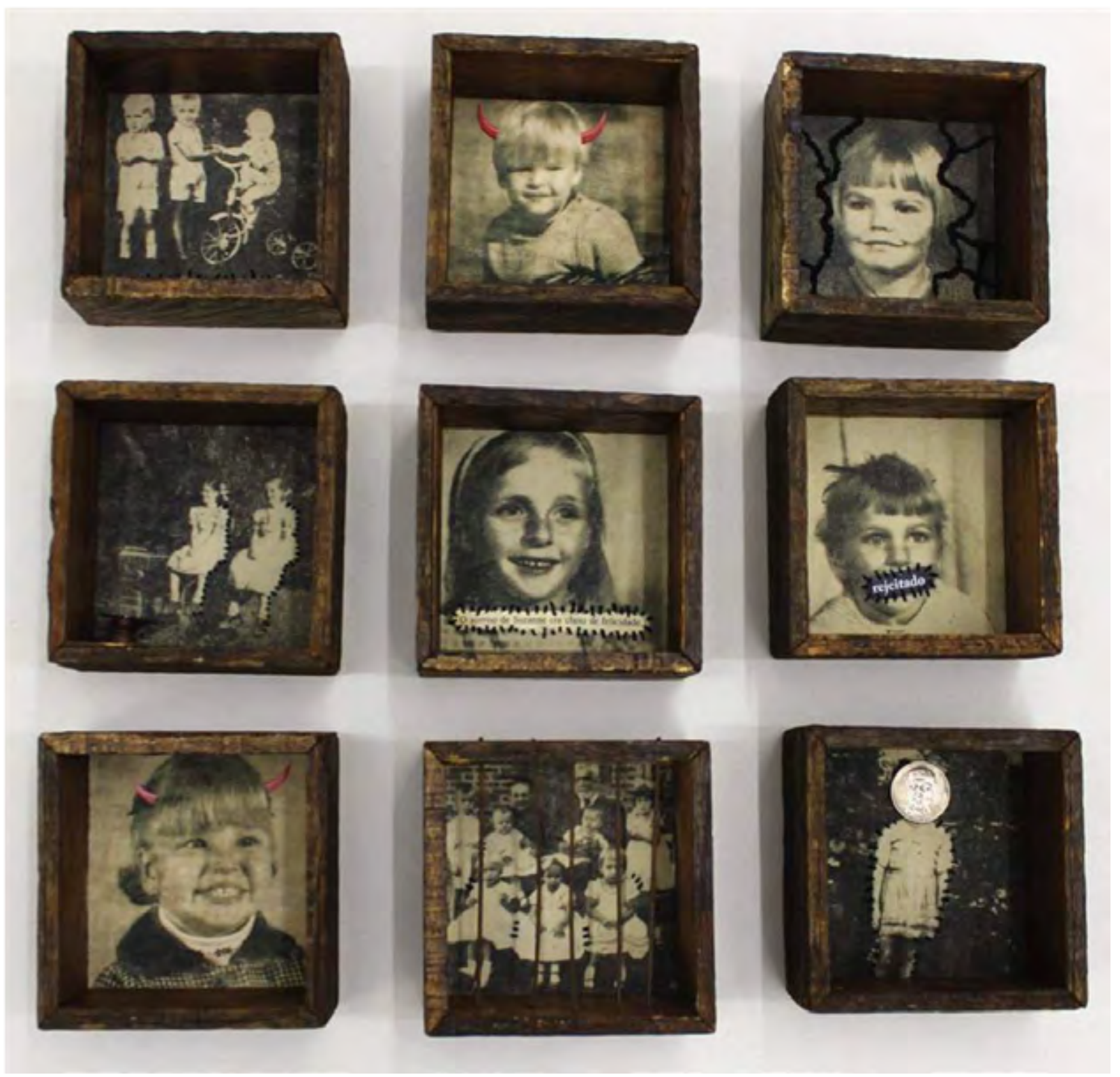

MARTINA BERGER

(São Leopoldo | RS)

martinaberger7@gmail.com

Infância Instantânea \#2, 2017

Cianotipia sobre tecido 100\% Algodão, tonalizada em erva-mate, com interferências de bordado, colagem e objetos $10 \times 10 \times 5 \mathrm{~cm}$ (cada) 

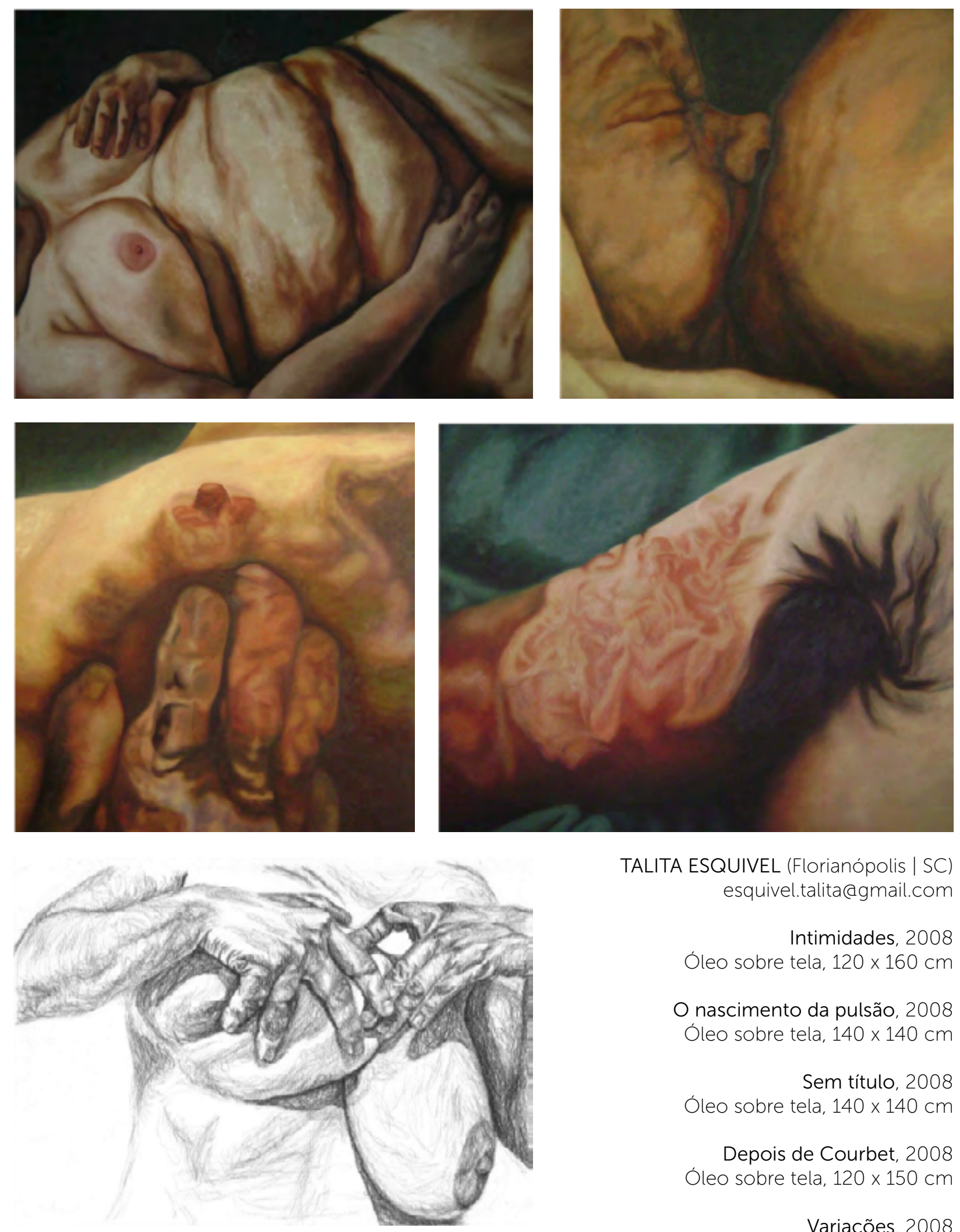

TALITA ESQUIVEL (Florianópolis | SC) esquivel.talita@gmail.com

Intimidades, 2008 Óleo sobre tela, $120 \times 160 \mathrm{~cm}$

O nascimento da pulsão, 2008 Óleo sobre tela, 140 × $140 \mathrm{~cm}$

Sem título, 2008 Óleo sobre tela, $140 \times 140 \mathrm{~cm}$

Depois de Courbet, 2008 Óleo sobre tela, $120 \times 150 \mathrm{~cm}$

Variações, 2008 Lápis sobre papel A3 

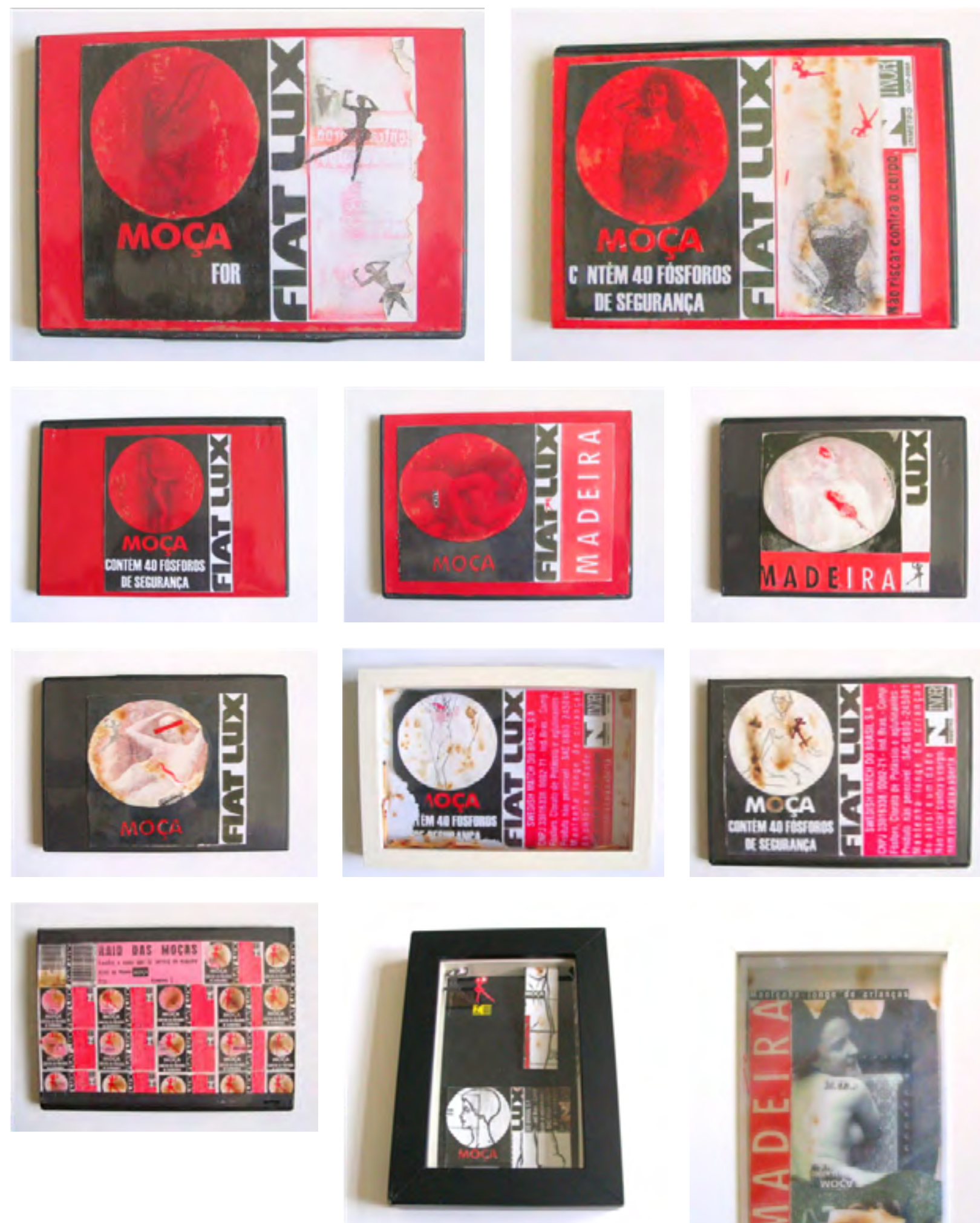

VLADIMIR OLIVEIRA (Salvador | BA)

vladso@hotmail.com

https://www.flickr.com/photos/vladportfolio/

Série Moças (Raid), 2007

Desenhos, Xerox, Ampliações, Impressões

Manuais, Recortes, Colagens e Queimas. 